\title{
Foundation of the Newborn Screening Translational Research Network and its tools for research
}

\author{
Michele Lloyd-Puryear, MD, $\mathrm{PhD}^{1}$, Amy Brower, $\mathrm{PhD}^{1}$, Susan A. Berry, $\mathrm{MD}^{2}$, \\ Jeffrey P. Brosco, MD, PhD ${ }^{3}$, Bruce Bowdish, $\mathrm{PhD}^{1}$ and Michael S. Watson, $\mathrm{PhD}^{1}$
}

In the past 20 years, several policy activities were undertaken that shaped today's newborn screening (NBS) programs and their associated NBS research activities: the Newborn Screening Task Force Report; the Child Health Act of 2000, Screening for Heritable Disorders; the American College of Medical Genetics and Genomics' (ACMG's) Newborn Screening Uniform Panel; and the ACMG expert panel to examine the development of a national collaborative study system for rare genetic diseases. These activities helped conceptualize the Newborn Screening Translational Research Network (NBSTRN) infrastructure and lay the foundation for its current activities. After 10 years, NBSTRN has grown into an organization that provides tools and resources for researchers to conduct research relevant to NBS programs for rare diseases for which data has been siloed locally. Infrastructure includes tools for the analytical and clinical validation of screening tests; the collection, analysis, sharing, and reporting of longitudinal laboratory and clinical data on newborn-screened individuals; and a webbased tool that allows researchers to acquire dried blood spots available for use in research from state NBS programs. NBSTRN also provides tools for researchers such as informed consent templates, disease registries, state NBS profiles, and consultation on planning pilot studies. In time, the growing data will become a resource itself.

Genetics in Medicine (2019) 21:1271-1279; https://doi.org/10.1038/s41436018-0334-8

Keywords: genetics; genomics; newborn screening; translational research; public health

\section{INTRODUCTION}

The system established in the United States for universally screening newborns for various mostly genetic congenital conditions is a public health triumph. Newborn screening (NBS) detects infants with various disorders and is comprised of prenatal education, hospital and laboratory based screening, diagnosis, and clinical care. Screening the newborn population also presents the opportunity to impact a disease process before the onset of a clinically recognizable disease and its clinical course.

Twenty years ago deliberate efforts (see Table 1) were begun to improve NBS programs and to improve the research base for NBS. ${ }^{1-8}$ At that time, NBS programs were at the cusp of dramatic changes: new screening technologies had greatly expanded the capacity for screening for multiple disorders using a single platform, challenging the concept of one test/ one condition; a draft of the genome was available and our knowledge base of genotype/phenotype relationships was beginning to expand; and traditional research models (single condition/single research site) were being challenged. Because most of the conditions on NBS panels are rare and typically defined by the clinical presentation of affected individuals, one cannot define the full range of disease expression, age of onset, penetrance, and treatment response, or find the genetic and environmental modifiers until a large population with the disorder is studied. The lack of unbiased knowledge about conditions hinders the assessment of outcomes across the phenotypic range of disease, including adult-onset forms. In addition, the need for pilots of screening technologies and treatments on unselected large populations such as all newborns increases the cost and decreases the feasibility of clinical trials. Research on rare conditions, therefore, requires an organized, collaborative, multisite, national-global effort to achieve statistically meaningful and unselected patient populations to obtain sound data for prevalence and surveillance measurements, and for therapeutics, screening, and diagnostic test development. Further, as we consider ways to expand NBS for the multitude of rare conditions, the most efficient way to enable the needed research is to develop a core infrastructure with centralized databases and accumulated expertise that could be used by any investigators working in this domain. ${ }^{7}$

\footnotetext{
${ }^{1}$ American College of Medical Genetics and Genomics, Bethesda, MD, USA; ${ }^{2}$ Departments of Pediatrics and Genetics, University of Minnesota, St. Paul, MN, USA; ${ }^{3}$ Department of Pediatrics, University of Miami, Miami, FL, USA. Correspondence: Michael S. Watson (mwatson@acmg.net)
} 
Table 1 Timeline of NBS national policy development

\begin{tabular}{|c|c|c|c|}
\hline Policy & Date & Outcomes & Impact \\
\hline $\begin{array}{l}\text { 1. AAP Newborn } \\
\text { Screening Task } \\
\text { Force }^{1}\end{array}$ & $\begin{array}{l}\text { Publication } \\
\text { of report, } \\
2000\end{array}$ & $\begin{array}{l}\text {-Child Health Act of } 2000\left(\text { ref. }^{2}\right) \text {; signed into law } 2000 \bullet \\
\text { Heritable Disorders Program established }\end{array}$ & $\begin{array}{l}\text {-AAP Task Force brought forth recommendations that } \\
\text { provided a basis for state uniformity and an outline for a } \\
\text { research agenda } \bullet \text { Established the ACHDNC } \bullet \text { Established } \\
\text { programs at NIH, CDC, and HRSA }\end{array}$ \\
\hline $\begin{array}{l}\text { 2. ACMG } \\
\text { Newborn } \\
\text { Screening Expert } \\
\text { Panel } 3,4\end{array}$ & $\begin{array}{l}\text { Publication } \\
\text { of report, } \\
2006\end{array}$ & $\begin{array}{l}\text {-ACMG NBS Expert Panel brought forth } \\
\text { recommendations that provided a basis for state } \\
\text { uniformity and an outline for a research agenda }\end{array}$ & $\begin{array}{l}\bullet \text { RUSP adopted by ACHDNCo } \\
\text { Panel almost uniformly adopted by States } \bullet \text { Mandate to } \\
\text { follow RUSP added to some state policies } \bullet \text { ACHDNC } \\
\text { modeled evidence review on ACMG report }\end{array}$ \\
\hline 3. NBSSLA $2008^{8}$ & $\begin{array}{l}\text { Signed into } \\
\text { law, } 2008\end{array}$ & $\begin{array}{l}\text {-The Hunter Kelly Newborn Screening Research Program, } \\
\text { established at the NIH, was a critical component of the } \\
\text { NBSSLA }\end{array}$ & $\begin{array}{l}\text {-NICHD funding opportunitieso } \\
\text { Natural Historyo } \\
\text { Technology Developmento } \\
\text { Treatment Developmento } \\
\text { Genomicso } \\
\text { Pilots }\end{array}$ \\
\hline
\end{tabular}

A key component of the National Institutes of Health (NIH) Eunice Kennedy Shriver National Institute of Child Health and Human Development's (NICHD) Hunter Kelly Newborn Screening Program is the Newborn Screening Translational Research Network (NBSTRN). As a translational research network, NBSTRN was conceptualized to develop and share resources and infrastructure to support NBS researchers. ${ }^{5,6}$ NBSTRN has become a mechanism for research with NBS blood samples/dried blood spots (DBS), evaluating laboratory technology performance, establishing pilot studies for NBS of new conditions, and longitudinal natural history investigations of NBS conditions. The American College of Medical Genetics and Genomics (ACMG) is in the eighth year of its current agreement with NIH/NICHD to create the NBSTRN and operates the NBSTRN Coordinating Center (NBSTRN-CC).

In this paper, we review the genesis and accomplishments of NBSTRN over the first 8 years of the initiative and future plans for this network.

\section{THE HUNTER KELLY NEWBORN SCREENING RESEARCH PROGRAM AND NBSTRN}

The NIH/NICHD established the NBSTRN-CC in 2008, with an expectation that a shared research infrastructure would allow more investigators to work in this area at lower total cost than funding similar core functions for individual grantees. ${ }^{5,6}$ The collective research infrastructure provides a mechanism for an unbiased understanding of rare genetic conditions across the lifespan, population-based pilot testing of new NBS tests, new technology development and application, and new therapeutics development. This research infrastructure also strengthens and enables expansion of NBS programs in a more systematic fashion.

Research needs for NBS were addressed formally in federal legislation with an amendment to the Public Health Service Act. The amendment created the Newborn Screening Saves Lives Act (NBSSLA) 2008 (HR 3825) and within the legislation, the Hunter Kelly Newborn Screening Research Program. ${ }^{8}$ This research program authorized the NIH to continue research that would benefit NBS programs by:

Identifying, developing, and testing the most promising new screening technologies

Promoting the study of experimental treatments and disease management strategies for additional newborn conditions that can be detected through NBS for which treatment is not yet available

Encouraging other activities that would improve NBS

NBSSLA was reauthorized and amended in 2014, and expanded the Hunter Kelly Newborn Screening Research Program requiring the "provision of research findings and data for newborn conditions under review by the Advisory Committee on Heritable Disorders in Newborns and Children (ACHDNC) to be considered for addition to the recommended uniform screening panel (RUSP)." ",10 NBSSLA 2014 also required NIH to conduct "pilot studies on conditions recommended by the ACHDNC to ensure that screenings are ready for nationwide implementation." 
Table 2 Mission Statement and Goals of the Newborn Screening Translational Research Network (NBSTRN)

The Mission of the Newborn Screening Translational Research Network is to improve the health outcomes of newborns with genetic or congenital disorders by means of an infrastructure that allows investigators access to robust resources for newborn screening research.

1.To enable biomedical investigators, with appropriate institutional review board (IRB) permission and privacy protections, to access dried blood spots and other biological specimens in a site-independent manner for research

2.To support the needs of investigators to:

oEvaluate the predictive value of biomarkers through early phase clinical/epidemiological studies

oFacilitate the development and assessment of new methods and technologies to improve the capacity for early identification through newborn screening

oldentify candidate diseases for inclusion in expanded newborn screening

oDetermine the effectiveness of treatments and long-term outcomes by means of studies involving screened and treated patients

3.To encourage collaboration among researchers and rapid dissemination of information to promote progress and avoid fragmentation of effort

4. To develop policies and procedures that support privacy and confidentiality of patient-related information as well as appropriate rules by which to conduct the research

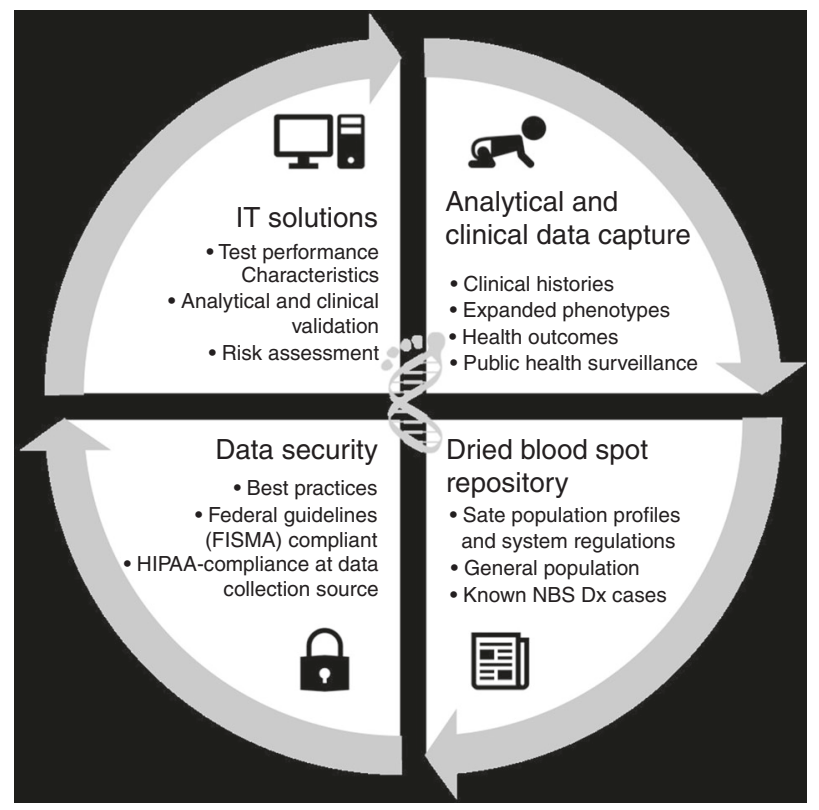

Fig. 1 Four key components of the Newborn Screening Translational Research Network Coordinating Center (NBSTRN-CC) infrastructure. Dx diagnosis, FISMA Federal Information Security Management Act, HIPAA Health Insurance Portability and Accountability Act of 1996, IT information technology, NBS newborn screening

\section{DEVELOPMENT OF THE COORDINATING CENTER AND IMPLEMENTATION OF ITS RESOURCES}

The first 5-year contract for the NBSTRN-CC in 2008 had the following requirements:

- Establish an organized network of state NBS programs and clinical centers.

- Develop an informatics system to support research. This informatics system was to integrate with established national clinical center networks (see "Security and privacy system requirements") and enable the collection of personal health information (PHI) as needed.

- Establish either a physical or virtual repository of dried blood spots (VRDBS) for research (see section on VRDBS below).
- Facilitate research on the development of new screening methods and on screened and treated patients to define the effectiveness of treatments and long-term health outcomes.

- Provide expertise for researchers on statistical analysis, clinical trial design, and regulatory requirements associated with various ethical and legal issues (e.g., informed consent).

- Disseminate research findings and reports and publications related to the activities of the NBSTRN-CC.

- Establish a steering committee with expertise required by the project.

During its first year, the NBSTRN-CC developed a mission statement for the project and built an infrastructure that ultimately fulfilled the contractual statement of work and set concrete goals to ensure that the NBSTRN became a fully functioning entity capable of supporting NBS researchers and the expected types of research they do (Mission Statement and Goals, see Table 2). The NBSTRN-CC established a steering committee that offered guidance to the $\mathrm{CC}$ and set up multiple workgroups to bring expertise to the NBSTRN-CC on specific issues. Focused efforts during the first 3 years were on the development of basic infrastructure needed for the NBSTRN project (Fig. 1), i.e., creation of an interactive website, and building the information technology and informatics infrastructure that supports the repository of dried blood spots, meets data privacy and security requirements for the project, and has the capacity to collect case-level and longitudinal condition-specific data. ${ }^{11}$ NBSTRN also recruited subject matter experts for each of the conditions that were part of the RUSP. ${ }^{10}$ In addition, NBSTRN undertook an assessment of the ability and capacity for state NBS programs to conduct research and examinations of ethical and legal issues around state and federal policies for informed consent and research in the NBS population. From 2008 to 2011, a total of almost 200 experts and stakeholders from across the country (representing clinical care and public health professionals, lay advocates, NBS, informatics, genetics/genomics, researchers, and federal agencies) and team members from 
the 52 NBS programs in the United States were recruited to participate in the steering committee and workgroups focused on laboratory screening, informatics, clinical care, and bioethical and legal issues. Many of the clinical experts, researchers, and ethical, legal, and social implications (ELSI) professionals were from institutions involved in national clinical research efforts including (1) Regional Genetics Networks (RGNs), (2) Clinical and Translational Science Award sites, and (3) Rare Diseases Clinical Research Network consortia (e.g., Primary Immune Deficiency Treatment Consortium, Lysosomal Disease Network).

The NBSTRN-CC also built relationships with state NBS programs and the clinical research and practice communities across multiple specialties providing care for newborns with screened conditions. While each pilot has its own network, the overall coordinating effort is through the Clinical Centers Workgroup (see section on Longitudinal Pediatric Data Resource [LPDR] below). By the end of the first 5-year contract in September 2013, NBSTRN-CC tools were developed, implemented, and made available to researchers including the VRDBS, LPDR, and the adaptation of the Region 4 Stork system (R4S) housed at the Mayo Clinic for clinical and NBS laboratory improvement for prospective use in pilot studies of new conditions and technologies in NBS to establish screening test performance characteristics. The second 5-year contract with ACMG began in fall 2013 and continued with many of the same essential tasks under the first contract, with new requirements by NIH/NICHD to (1) work with partners to develop and use common data elements (CDEs) for NBS conditions and (2) maintain a data repository that securely houses genomic data, variant call files from genome and exome sequencing, and key phenotypic data for subjects followed within the long-term follow-up data set in the LPDR along with information on sequencing and annotation methodology.

The NBSTRN-CC focused on building web-based interactive resources for researchers that could be shared and continuously updated as disease understanding advances and technology improves. ${ }^{11}$ In addition, a uniform registration system was created that includes a detailed interview with researchers to capture their hypotheses, research plans, analysis needs, and dissemination goals. A subset of website pages are public facing, but registration and preapproval are required before access is granted to VRDBS, LPDR, and the R4S performance database. These resources are available on the ACMG/NBSTRN-CC website. ${ }^{11}$

The NBSTRN now offers a centralized mechanism for state-based NBS programs to obtain evidence for their decision-making processes. Because the context of NBS is not static, programs are able to evaluate evidence in an ongoing manner to make decisions regarding screening for new conditions and adoption of novel technologies. Prior to the NBSTRN, the evidence for conditions was often based on case reports and small observational studies; ascertainment through "normal" populations was limited; data was often siloed in separate locations and could not be shared; and sample sizes were small and biased by ascertainment of affected individuals and lacked sufficient statistical power, leading to limited understanding of penetrance, clinical course, and effective treatments. NBSTRN's information technology (IT) tools have been used in 26 research projects, in 30 clinical sites located in 22 states, and in multistate pilots of four conditions collectively screening over 1.2 million births.

\section{Security and privacy system requirements}

The NBSTRN suite of IT solutions must satisfy NIH requirements, and thus requires adherence to federal policies for information security protections outlined under the Federal Information Security Management Act (FISMA) of 2002 (Public Law 107-347) and FISMA 2014 through OMB Circular A-130 (ref. ${ }^{12}$ ). These policies outline requirements for developing and operating information technology (IT) systems based on data type, how the data is to be used, and its risk impact, and there are three security categories-low, moderate, or high. After NIH review, ACMG received authority to operate (ATO) the IT environments needed to offer NBSTRN IT solutions including (1) VRDBS and R4S as FISMA Low because they do not contain PHI and (2) the LPDR as FISMA Moderate because LPDR allows the capture of PHI. The ACMG IT environment integrates on-site resources with cloud resources and the system has

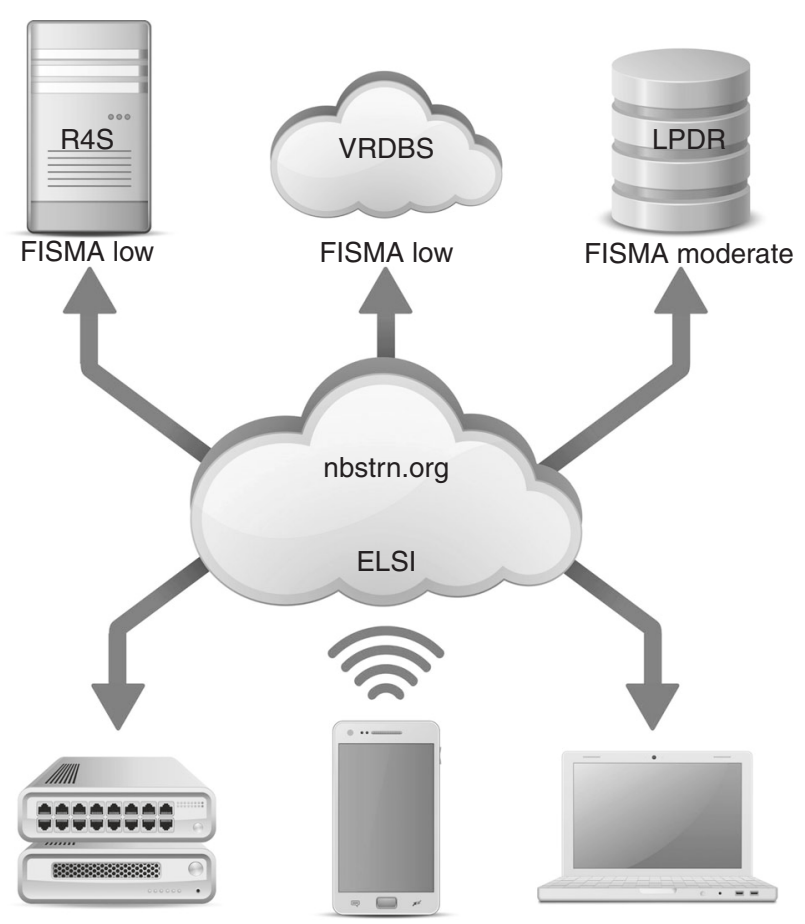

Fig. 2 Newborn Screening Translational Research Network (NBSTRN) information technology (IT) environment with security and compliance covering Federal Information Security Management Act (FISMA) Low and FISMA Moderate. ELS/ ethical, legal, and social implications; LPDR Longitudinal Pediatric Data Resource; R4S Region 4 Stork Project; VRDBS Virtual Repository of Dried Blood Spots 
implemented vulnerability scanning, security control assessments, and controlled access (Fig. 2). ACMG submits a quarterly review of the security of IT system to NIH/NICHD. Cumulatively this provides researchers with a certified and accredited informatics infrastructure to facilitate protected and secure collection, analysis, and dissemination of NBS research data. Compliance with the Health Insurance Portability and Accountability Act (HIPAA) falls to those working directly with individuals.

\section{Virtual Repository of Dried Blood Spots (VRDBS)}

The VRDBS is a web-based tool that allows investigators to quickly learn what DBS from state NBS programs may be available for use in research. DBS are a unique biospecimen resource that reflects the environmental, nutritional, genetic, and biochemical status of the newborn. ${ }^{13}$ The residual DBS have been an invaluable resource for testing and refining new technologies to detect conditions already included in NBS. They also are needed to develop new tests for conditions not already included in NBS. The residual DBS specimens themselves are held under the stewardship of state public health programs that can allow them to be accessed by investigators who comply with requirements of the specific states within their material transfer agreements. VRDBS allows various approved stakeholders the opportunity to access NBS residual DBS information, and communicate with state NBS personnel and NBSTRN to strengthen research design proposals. States deposit information for each DBS available for research, including de-identified data elements of interest to NBS researchers as well as quality indicators to help insure reproducibility of scientific results, creating an online repository. Creation of the VRDBS resulted in $3,323,929$ general population DBS and 16,561 DBS characterized from infants with one of the 47 NBS conditions listed in the VRDBS. Approved users have access to this catalog of specimens for NBS-related research and program development. NBS personnel from NBSTRN partner states have assisted researchers with specific study questions, provided information about the processes they require for material transfer agreements, written letters of support, and assisted with physically accessing DBS.

In the first quarter of 2015, NBSSLA 2014 went into effect. It included two significant changes to the human subjects regulations related to research with DBS. The changes required that research using DBS be considered human subject research and eliminated the ability of the institutional review board (IRB) to waive informed consent for research involving newborn DBS. This halted the addition of DBS specimens collected after 16 March 2015 to the VRDBS and prompted NBSTRN to accelerate development of an interactive web-based resource addressing ELSI relevant to NBS researchers. ${ }^{13}$ Currently 158 individuals are registered to use the VRDBS representing four user groups (30\% academic, $24 \%$ public health, $23 \%$ industry, and $23 \%$ nonprofit) and seven NBS researchers submitted nine study protocols (two investigators submitted two protocols).

\section{Longitudinal Pediatric Data Resource (LPDR)}

The LPDR is a web-based suite of IT tools designed to enable the collection, analysis, sharing, and reporting of longitudinal laboratory and clinical data on newborn-screened individuals. ${ }^{14}$ Because a central responsibility of the NBSTRN-CC is to facilitate the translation of new findings into clinical care, a mechanism to understand the impact of adoption of NBS on health outcomes is critical. Equally critical is long-term alignment with electronic health record (EHR) systems to facilitate data extraction and move away from secondary databases. To meet this need, the NBSTRN Clinical Centers Workgroup developed the LPDR by forming teams of experts to create consensus-based, common, and standardized CDEs. The Clinical Centers Workgroup partnered with a public health workgroup of the Health Resources and Services Administration's Regional Genetic Service and Newborn Screening Collaboratives (now the RGNs) to develop CDEs for $80 \%(46 / 57)$ of the conditions that were part of the ACHDNC's RUSP. ${ }^{10}$ The Clinical Centers Workgroup also developed CDEs for researchers pilot testing six conditions that were candidates for routine NBS. The LPDR uses REDCap to collect data using electronic case report forms (eCRFs) that incorporate the CDEs into dropdown menus. The CDEs were made available to the National Library of Medicine (NLM) for integration into EHR standards for the US and the NBS Coding and Terminology Guide. ${ }^{15,16}$ A data almanac was created that contained semantic definitions, annotations, and standardization to improve the quality of the data collected by each investigator. It contains 15,685 data elements and currently 3745 elements have definitions and, where applicable, Logical Observation Identifiers Names and Codes (LOINC), Systematized Nomenclature of Medicine-Clinical Terms (SNOMED CT), and the International Classification of Diseases, Ninth or Tenth Revision (ICD-9 or 10) codes. The data almanac also enables new researchers to adopt the consensus-based CDEs, generate case report forms, and suggest additional CDEs for new conditions, technologies, and treatments. To support the analysis of the accumulated clinical data, the LPDR includes a data discovery tool for researchers to build use cases and test hypotheses using their own data sets or share data sets with other research groups. The LPDR includes a genomic data platform that provides annotated variant-level data exploration to further understanding of the use of genomics in the newborn period. LPDR supports both centralized and local data collection, which enables NBS researchers to conduct studies within their own IT environment. Across the LPDR projects, clinicians from over 80 hospitals and care centers have entered data using the NBSTRN CDE sets built into eCRFs. Some clinicians have created templates within their EHRs to collect CDEs, and we have worked with two of the RGNs to trial an alert flag as a reminder to enter data into the 
major EHR systems (Epic, Cerner). ACMG has been involved in discussions to create a genetic-focused template for Epic.

\section{Laboratory performance database (Region 4 Stork [R4S] Project)}

NBSTRN uses R4S as an online data collection and analysis system that supports the development of appropriate tools for the analytical and clinical validation for novel and existing screening tests used in the newborn period. ${ }^{17,18} \mathrm{R} 4 \mathrm{~S}$ began as a performance improvement tool of NBS by tandem mass spectrometry (MS/MS) in 2004 and included postanalytical interpretive tools that integrated all informative results into a single score and compared results with known confirmed cases to return a percentile ranking as a measure of likelihood of disease. The R4S database grew to include in excess of 21,000 cases contributed from more than 269 public health programs and private labs from 69 countries. ACMG leveraged the widely utilized R4S software to support the analytical and clinical validation of new screening technologies. ${ }^{17}$ In 2013, the Mayo Clinic, which developed, maintains, and owns the R4S website and databases platform, exempted newborn screening uses and NBSTRN from enforcement of its patents on the system thereby making it freely available to the NBS research and service community. Two R4S databases, or applications, were created as a result of utilizing the R4S software specifically for assisting researchers in pilot study projects: Severe Combined Immunodeficiency Disorder (SCID) and Lysosomal Storage Disorders (LSD). This webbased application for the collection and reporting of analytical results has been developed and widely adopted into the routine practice of newborn screening laboratories worldwide. At the Mayo Clinic, R4S has now evolved into a secondgeneration tool called the Collaborative Laboratory Integrative Reports (CLIR), and is based on the concept of the R4S modules but includes improvements through the use of covariate-adjusted results for age, birth weight, and sex. ${ }^{18}$ CLIR integrates complex patterns of test results into a single score and the score is assessed against a threshold of clinical significance; when found informative, this represents the likelihood of disease.

\section{Use of R4S/CLIR, LPDR, and VDRBS tools}

Research efforts supported by the Hunter Kelly Newborn Screening Research Program through grants and contracts were encouraged to use NBSTRN resources and infrastructure for their projects. Twenty-three published papers have mentioned the use of NBSTRN resources and/or tools (27\% LPDR, 23\% pilots, 23\% NBSTRN, 10\% VRDBS, 7\% policy, 5\% R4S, 5\% ELSI) and two recent papers reference the availability of data sets in the LPDR. ${ }^{19-33}$ While not inclusive of all of the projects funded under Hunter Kelly NIH or other programs funded by the federal Department of Health and Human Services (HHS), the examples listed illustrate how the NBSTRN-CC resources are being exploited and the benefits of creating a network of experts across disciplines and venues. Additional projects and publications from these projects can be seen at the NBSTRN website. ${ }^{11}$ All of these efforts were reviewed by the NBSTRN steering committee and various workgroups with guidance provided where needed:

Inborn Errors of Metabolism Collaborative (IBEMC): The IBEMC investigators collaborated with NBSTRN in generating and deploying the LPDR for use in their project designed to collect longitudinal data on the clinical progress of persons a/presymptomatic or affected with conditions identified by newborn screening, focusing on inborn errors of metabolism. ${ }^{34}$ Every week thousands of data points were collected from 22 clinics in 14 states using the LPDR module. This project illustrates the use of LPDR to (1) investigate the relationship among newborn screen data, genotype, and early manifestations as well as complications of inborn errors of metabolism; (2) evaluate the impact of early identification and intervention on metabolic conditions; (3) inform decision making about optimal public health investment in newborn screening; (4) clarify the previously undefined clinical history of treated and untreated very rare metabolic conditions; and (5) identify the current nutritional and therapeutic interventions for children with metabolic conditions and evaluation of their effectiveness. The complete IBEMC data set is available for secondary research through the NBSTRN.

SCID Pilot Study: From 2010 to 2011, NBSTRN provided the administrative core for this project and used its convening power to bring participants and experts together to define parameters for data collection while a contract supplement to New York State supported screening costs in participating states. ${ }^{35}$ The project used both the LPDR and R4S. The inclusion of diagnostic information was an expansion of the R4S system that enabled clinical validation and furthered scientific understanding of the immunological disorders identified by SCID NBS. The analytical and clinical definitions are now being used by states as they implement SCID newborn screening and were included in a Clinical and Laboratory Standards Institute (CLSI) guidance document. ${ }^{36}$ During the 8-month study, 654,053 babies were screened, and 307 were referred for diagnostic assessment. A total of 12 babies were confirmed with SCID, 3 babies were confirmed with a SCID variant, and 38 babies were confirmed with an immunodeficiency related to another condition. ${ }^{37}$

LSDs: This was a 5-year effort to conduct a pilot newborn screening for several LSDs in approximately 80,000 infants born in New York City hospitals to validate the screening assay for LSDs and to define the natural history of these disorders. ${ }^{38}$ NBSTRN coordinated a workgroup chaired by the lead researcher to develop the LPDR to enable longitudinal studies and data aggregation for pilots of these disorders. These data sets are now in use by several state-based NBS programs as nationwide screening for several of these conditions is implemented.

In addition, the NBSTRN has been an explicit part of NIH/ NICHD efforts to promote research in NBS. For example, 
in 2016 the NIH/NICHD created a pool of three states to conduct NBS pilots to facilitate the implementation of conditions recently added to routine newborn screening by ACHDNC, utilizing the coordinating infrastructure of NBSTRN. These projects are implementing NBS for Pompe (glycogen storage disease type II), mucopolysaccharidosis (MPS) type I, and X-linked adrenoleukodystrophy. NBSTRN-CC coordinates monthly conference calls, facilitating adoption of R4S/CLIR and LPDR for use in the pilots and clinical outcome studies. These implementation pilots generate valued resources to accelerate and support the adoption of screening for these conditions and reduce the potential for disparity for both the early identification of disease and the initiation of life-saving treatment across the United States.

Finally, NBSTRN-CC also has served in an administrative capacity for NIH/NICHD-NHGRI cofunded Newborn Sequencing in Genomic Medicine and Public Health program (NSIGHT) grantees. ${ }^{39}$ NSIGHT was established to explore the implications, challenges, and opportunities associated with the use of genomic sequence information in the newborn period. Three research approaches were used: (1) acquisition and analysis of genomic data sets that expand considerably the scale of data available for analysis in the newborn period, (2) clinical research that will advance understanding of specific disorders identifiable via newborn screening through promising new DNA-based analysis, and (3) research related to ELSI issues in genomic sequencing of newborns. The NSIGHT teams plan to utilize LPDR to house clinical and genomic data to conduct crosscohort analysis of newborns from the accumulated populations of healthy newborns, newborns with a RUSP condition, newborns with atypical SCID, and newborns in the neonatal intensive care unit.

Some non-NIH-funded projects have also requested utilization of NBSTRN-CC resources for their own projects:

The Sickle Cell Disease Newborn Screening Program aggregates information in the LPDR from individuals living with sickle cell disease and enables community-based organizations to provide care coordination and improve health outcomes by assessing access to a quality medical home, education, and treatment.

The California Department of Public Health instituted the Primary Congenital Hypothyroidism ( $\mathrm{PCH}$ ) Project to understand health outcomes in young children diagnosed with $\mathrm{PCH}$ through NBS using an electronic survey delivered from a state-based NBS program to pediatricians and family practice clinicians. California used NBSTRNCC's LPDR to enable its NBS program to track health outcomes. Given the widespread calls for increased monitoring and research on long-term outcomes of NBS programs, this use of the LPDR represents a critical model for improving lifelong care coordination and quality improvement. ${ }^{40-42}$

\section{NEWBORN SCREENING SAVES LIVES ACT AND ITS 2014 REAUTHORIZATION: CHALLENGES}

The Newborn Screening Saves Lives Act Reauthorization 2014 (NBSSLA) was signed on 18 December 2014 and went into effect on 15 March 2015 (ref. ${ }^{9}$ ). While the NBSSLA reauthorized many portions of the previous 2008 authorization, it added a new provision, Section 12, to address research uses of nonidentified newborn residual DBS. The NBSSLA created a special regulatory designation of DBS under 45 C.F. R. 46, the Federal Policy for the Protection of Human Subjects (often referred to as the Common Rule) and placed restrictions on IRB authority regarding research with DBS. ${ }^{43}$ Section 12 prohibited waiver of consent in the use of DBS even where there is little or no risk in the research and where research cannot practicably be done if documentation of written consent is required as is common for large distributed population studies. This amendment reversed established IRB and Office of Human Research Protections (OHRP) practice in the general research setting using anonymized specimens. Furthermore, Section 12 seemed to impact the use of anonymized residual DBS for program operation purposes, such as surveillance, test development, or feasibility studies. Given the lack of evidence of any adverse effects on individuals whose DBS have been used for these purposes, the NBS community (researchers, providers, parents, and public health) encouraged OHRP to include a statement in the Common Rule that defines the term "research" in a way that excludes NBS program operations and permits research on anonymized specimens without specific written consent.

By statute, the changes made by the NBSSLA in 2015 applied only until revision of the Common Rule (federal regulations governing human subjects research) were promulgated. A final rule was published on 18 January 2017 and would have vacated the changes made by the NBSSLA on the effective date of the new Common Rule, 19 January 2018 (ref. ${ }^{44}$ ). After several delays, the HHS announced the implementation of the final revisions to the Common Rule would be officially delayed until 21 January 2019. Because of the lack of clarity, the following key issues remain unresolved for NBS research:

Uses of nonidentified biospecimens. This decision could allow the NBS community to continue to use nonidentified DBS in all aspects of NBS program operations.

Whether clinical trials that are not federally funded are covered by the final rule.

Use of broad consent (i.e., seeking prospective consent to unspecified future research) from a subject for storage, maintenance, and secondary research use of identifiable private information and identifiable biospecimens is allowed. Broad consent is an optional alternative that an investigator may choose instead of conducting the research on nonidentified information and nonidentified biospecimens, having an IRB waive the requirement for informed consent, or obtaining consent for a specific study.

Use of data from secondary research with nonidentified 
newborn DBS would be treated in the same way as secondary research with any other type of nonidentified biospecimen. Such research would not be considered research with human subjects under the final rule so would not be subject to the rule.

\section{FUTURE CHALLENGES}

As NBS expands and improves, pilot testing of new candidate conditions will be necessary. For the best long-term decisions to be made about expansion, well-controlled implementation pilots in large populations will be needed to make meaningful information available to ACHDNC as they conduct evidencebased reviews of additions to the RUSP. Prospective population-based studies with an endpoint of detecting rare disease patients are expensive to perform and are challenged by the constraints of human research protections. Carefully managed research in the NBS environment offers unique opportunities to better understand the nature of genetic and nongenetic diseases. Unlike populations ascertained through clinical encounters, which have an inherent bias toward those who are clinically affected and toward more severe disease expression, identification through NBS allows an unbiased assessment of the full spectrum of NBS.

Research often is viewed differently by those in whom severe disease has occurred as compared with those who have not experienced these diseases themselves or within their families. Families with personal experiences have a strong interest in supporting research that could lead to improved outcomes for their affected family member or other families to come. Clearly, harnessing an interest in research from disease/lay advocacy communities, while protecting the interests of all who participate in newborn research, is essential. Laws and regulations cannot do all the work necessary for privacy protections. The NBSTRN-CC and researchers participating in the NBSTRN have an opportunity to facilitate novel methods for educating, informing, and consenting potential participants in research so that parents/ individuals can make informed choices for themselves or for their infants and children.

Communication with the public about the nature of NBS research, including both advocacy organizations and research participants, remains a challenge in the 21st century. NBSTRN-CC works with a variety of community partners, including Parent Project Muscular Dystrophy, Legacy of Angels Foundation, SCID Angels for Life, Genetic Alliance, and Hunter's Hope, to help educate stakeholders and build community engagement. For example, NBSTRN-CC has begun a newsletter that will facilitate communication with research participants by providing information on what has been learned as a result of their willingness to participate.

The NBSTRN-CC offers a robust infrastructure for the full range of issues confronting NBS researchers, especially those researching rare disorders. The creation of NBSTRN has established centralized resources for facilitating access to DBS, collecting and sharing data, evaluating laboratory test performance, and understanding health outcomes in individuals with a condition identified through NBS. NBSTRN has created a systems-based approach for coordination of the research agenda for condition evaluation and approval/ disapproval for NBS, treatment(s)/management, and candidate-condition pilots with the ACHDNC and various federal agencies. This systems-based approach still requires establishment and use of centralized or federated institutional review boards and enlisting patient advocacy groups into patient-centered research models. Ultimately building such a system will enhance collaborative opportunities while distributing cost sharing and the sharing of resources across the public health and health-care delivery systems and the rare disease research communities.

\section{DISCLOSURE}

The authors declare no conflicts of interest.

\section{REFERENCES}

1. AAP Newborn Screening Task Force. Serving the family from birth to the medical home. Newborn screening: a blueprint for the future. Pediatrics. 2000;106;:389S-427S.

2. Children's Health Act. https://www.congress.gov/106/plaws/publ310/ PLAW-106publ310.pdf. Accessed 9 July 2018.

3. Watson MS, Mann MY, Lloyd-Puryear MA, et al. Newborn screening: toward a uniform screening panel and system. Executive summary. Pediatrics. 2006;117:S296-S307.

4. Watson MS, Mann MY, Lloyd-Puryear MA, et al. Newborn screening: toward a uniform screening panel and system. Genet Med. 2006;8(Suppl 1):1S-252S.

5. Alexander $D$, van Dyke P. A vision of the future of newborn screening. Pediatrics. 2006;117:S350-S354.

6. Alexander D, Hansen JW. NICHD research initiative in newborn screening. Ment Retard Dev Disabil Res Rev. 2006;12:229-315.

7. Watson MS, Epstein C, Howell RR, et al. Developing a national collaborative study system for rare genetic diseases. Genet Med. 2008;10:1-5.

8. Government Publishing Office. H.R. 3825 (110th): Newborn Screening Saves Lives Act of 2008. https://www.govtrack.us/congress/bills/110/ hr3825. Accessed 9 July 2018.

9. Congress.gov. H.R. 1281 -Newborn Screening Saves Lives Reauthorization Act of 2014. https://www.congress.gov/bill/113thcongress/house-bill/1281. Accessed 9 July 2018.

10. Health Resources and Services Administration, Federal Advisory Committees. http://www.hrsa.gov/advisorycommittees/mchbadvisory/he ritabledisorders/recommendedpanel/. Accessed 9 July 2018.

11. NBSTRN. https://www.nbstrn.org/ Accessed 9 July 2018.

12. Executive Order 13636: Improving Critical Infrastructure Cybersecurity. https://www.dhs.gov/sites/default/files/publications/dhs-eo13636-analytic -report-cybersecurity-incentives-study.pdf. Accessed 9 July 2018.

13. NBSTRN Virtual repository of Dried Blood Spots (VRDBS). https://www. nbstrn.org/research-tools/virtual-repository-of-dried-blood-spots. Accessed 9 July 2018.

14. NBSTRN Longitudinal Pediatric Data Resource (LPDR). https://www. nbstrn.org/research-tools/longitudinal-pediatric-data-resource. Accessed 16 July 2018.

15. REDCap Research Electronic Data Capture. https://www.project-redcap. org/resources/citations/. Accessed 9 July 2018.

16. U.S. National Library of Medicine Newborn Screening Coding and Terminology Guide. https://newbornscreeningcodes.nlm.nih.gov/. Accessed 16 July 2018.

17. NBSTRN Newborn Screening Translational Research Network. Laboratory Performance Database (LPDR). https://www.nbstrn.org/research-tools/ lab-performance-database. Accessed 9 July 2018.

18. Mayo Clinic - CLIR Collaborative Laboratory Integrated Reports. https:// clir.mayo.edu/Home/About. Accessed 9 July 2018. 
19. Ramsey D, Scoto M, Mayhew A, et al. Revised Hammersmith Scale for spinal muscular atrophy: a SMA specific clinical outcome assessment tool. PLoS One. 2017;12:e0172346.

20. Bailey DB, Armstrong FD, Kemper AR, et al. Supporting family adaptation to presymptomatic and "untreatable" conditions in an era of expanded newborn screening. J Pediatr Psychol. 2009;34:648-661.

21. Auchus RJ, Witchel SF, Leight KR, et al. Guidelines for the development of comprehensive care centers for congenital adrenal hyperplasia: guidance from the CARES foundation initiative. Int J Pediatr Endocrinol 2010;2010: 275213. Published online 2011 Jan 10.

22. Levy $\mathrm{H}$. Newborn screening conditions: what we know, what we do not know, and how we will know it. Genet Med. 2010;12:S213-S214.

23. McHugh D, Cameron CA, Abdneur JE, et al. Clinical validation of cutoff target ranges in newborn screening of metabolic disorders by tandem mass spectrometry: a worldwide collaborative project. Genet Med. 2011;13:230-254

24. Chien $\mathrm{YH}$, Chiang SC, Chiang KL, et al. Incidence of severe combined immunodeficiency through newborn screening in a Chinese population. Taiwan Yi Xue Hui Za Zhi. 2015;114:12-16.is this mansucript written in english? What is the formatting for articles not in English?

25. Buckley RH. The long quest for neonatal screening for SCID. J Allergy Clin Immunol. 2012;129:597-604.

26. Puck JM. Laboratory technology for population-based screening for severe combined immunodeficiency in neonates: the winner is T-cell receptor excision circles. J Allergy Clin Immunol. 2012;129:607-616.

27. Groft SC. rare diseases research: expanding collaborative translational research opportunities. Chest. 2013;144:16-23.

28. Camp KM, Lloyd-Puryear MA, Yao L, et al. Expanding research to provide an evidence base for nutritional interventions for the management of inborn errors of metabolism. Mol Genet Metab. 2013;109:319-328.

29. Vogel BH, Bonagura $V$, Weinberg GA, et al. Newborn screening for SCID in New York State: experience from the first two years. J Clin Immunol. 2014;34:289-303

30. Kwan A, Church JA, Cowan MJ, et al. Newborn screening for SCID and T Cell lymphopenia in California: results of the first two years. J Allergy Clin Immunol. 2013;132:140-150.

31. Hall PL, Marquardt G, McHugh DM, et al. Postanalytical tools improve performance of newborn screening by tandem mass spectrometry. Genet Med. 2014;16:889-895.

32. Baldwin AE. Retrospective assessment of prenatal alcohol exposure by detection of phosphatidylethanol in stored dried blood spot cards: an objective method for determining prevalence rates of alcohol consumption during pregnancy. Int J Alcohol Drug Res. 2015;4:131-137.

33. Forsyth R, Vockley CW, Edick MA, et al. Outcomes of cases with 3methylcrotonyl-CoA carboxylase (3-MCC) deficiency-report from the Inborn Errors of Metabolism Information System. Mol Gen Metab. 2016;118:15-20.

34. Gratome NIH. Collaborative defining the Natural History of Inborn Errors of Metabholism. http://grantome.com/grant/NIH/R01-HD069039-05. Accessed 9 July 2018.

35. NBSTRN Newborn Screening Translational Research Network. SCID Resources. https://www.nbstrn.org/resources/scid-resources. Accessed 9 July 2018.

36. CLSI. NBS06-Newborn Blood Spot Screening for Severe Combined Immunodeficiency by Measurement of T-cell Receptor Excision Circles. 1st Edition. https://clsi.org/standards/products/newborn-screening/documents/nb s06/. Accessed 9 July 2018.

37. Kwan A, Abraham RS, Currier R, et al. Newborn screening for severe combined immunodeficiency in 11 screening programs in the United States. JAMA. 2014;312:729-738.

38. LSD Project. https://www.nbstrn.org/supported-projects/lysosomal-storagedisorders-collaborative. Accessed 9 July 2018.

39. NSIGHT Program. http://www.genome.gov/27558493. Accessed 9 July 2018.

40. Kemper AR, Boyle CA, Aceves J, et al. Long-term follow-up after diagnosis resulting from newborn screening: statement of the US Secretary of Health and Human Services' Advisory Committee on Heritable Disorders and Genetic Diseases in Newborns and Children. Genet Med. 2008;10:259-261.

41. Hinton CF, Feuchtbaum L, Kus C, et al. What questions should newborn screening long-term follow-up be able to answer? A statement of the US Secretary for Health and Human Services' Advisory Committee on Heritable Disorders in Newborns and Children. Genet Med. 2011;13:861-865.

42. Hinton CF, Homer CJ, Thompson AA, et al. A framework for assessing outcomes from newborn screening: on the road to measuring its promise. Mol Genet Metab. 2016;118:221-229.

43. Common Rule. https://www.hhs.gov/ohrp/regulations-and-policy/regulations/ common-rule/index.html. Accessed 19 July 2018.

44. Common Rule published in 2017. https://www.federalregister.gov/ documents/2017/01/19/2017-01058/federal-policy-for-the-protectionof-human-subjects. Accessed 9 July 2018. 